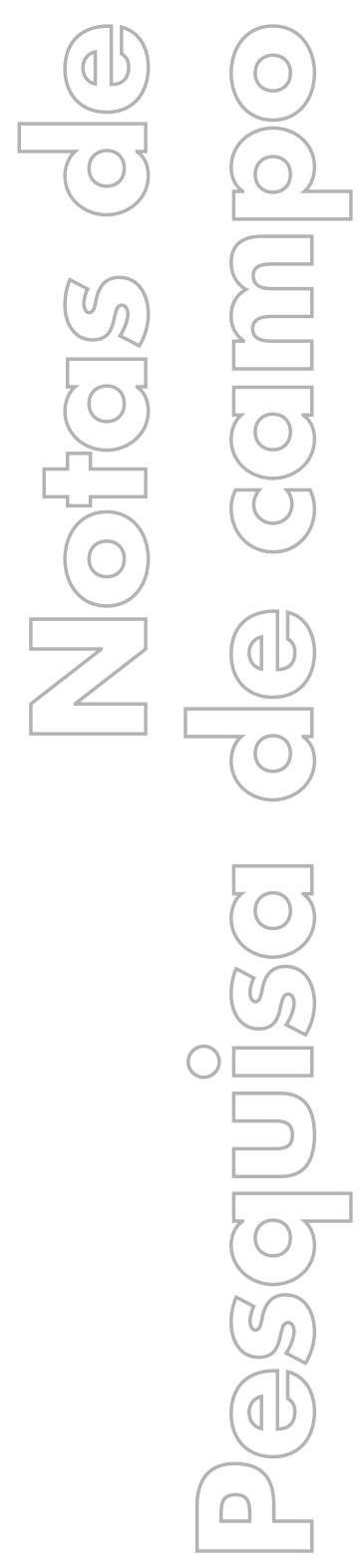

revista

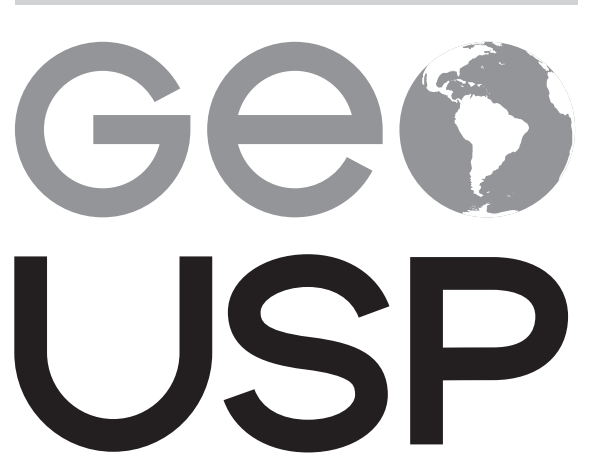

espaço e tempo

Volume $19 \cdot n^{\circ} 3$ (2015)

\section{Sensoriamento remoto e SIG aplicados ao mapeamento geomorfológico da bacia hidrográfica do córrego Indaiá-MS}

Elias Rodrigues da Cunha CPAQ-UFMS

Vitor Matheus Bacani CPAQ-UFMS

p. $630-646$

Como citar este artigo:

CUNHA, E. R.; BACANI, V. M. Sensoriamento remoto e SIG aplicados ao mapeamento geomorfológico da bacia hidrográfica do córrego Indaiá. Geousp - Espaço e Tempo (Online), v. 19, n. 3, p. 630-646 mês. 2016. ISSN 2179-0892.

Disponível em: URL: http://www.revistas.usp.br/geousp/ article/view/107612. DOI: http://dx.doi.org/10.11606/ issn.2179-0892.geousp.2015.107612.

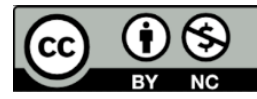

Este artigo está licenciado sob a Creative Commons Attribution 4.0 License. 


\title{
Sensoriamento remoto e SIG aplicados ao mapeamento geomorfológico da bacia hidrográfica do córrego Indaiá-MS
}

\section{Resumo}

O objetivo deste trabalho é caracterizar as formas de relevo da bacia hidrográfica do córrego Indaiá, localizada no município de Aquidauana-MS e cuja área é de aproximadamente $94,97 \mathrm{~km}^{2}$. Entre os procedimentos técnicos científicos adotados, aplicaram-se a proposta metodológica de taxonomia do relevo elaborada por Ross (1992) e Florenzano (2008), o manual técnico de geomorfologia (IBGE, 2009) e as rotinas de tratamento digital de imagem descritas em Novo (2008). A compartimentação geomorfológica foi elaborada a partir de produtos cartográficos intermediários derivados de análises fisiográficas (imagens dos satélites Landsat 5-TM e GeoEye) e morfométricas apoiadas em dados do radar interferométrico SRTM (Shuttle Radar Topographic Mission). A cartografação geomorfológica foi caracterizada até $05^{\circ}$ táxon, identificando-se as seguintes unidades de relevo e respectivas formas (vertentes): planície fluvial; colinas convexas com declividades de até 6\%; colinas convexas com declividades entre 6\% e 12\%; colinas convexas com declividades entre $12 \%$ e $20 \%$; morrote de topo convexo e morro de topo convexo. Entre as unidades mapeadas, predominam relevo dissecado em colinas de vertentes convexa em aproximadamente $90 \%$ da área da bacia associadas a inclinações que não ultrapassam 20\%, sustentadas na Formação Furnas e Formação Aquidauana, constituídas essencialmente por arenitos de granulação média avermelhada.

Palavras-chave: Mapeamento Geomorfológico. Taxonomia do Relevo. Sensoriamento Remoto. SIG. Córrego Indaiá.

\section{Remote sensing and GIS applied to geomorphological mapping of the hydrographic basin of the Indaiá-MS stream}

\begin{abstract}
The aim of this study was to characterize the landforms watershed stream Indaiá localized in Aquidauana-MS, whose area is approximately $94.97 \mathrm{~km}^{2}$. Technical scientific procedures employed consisted in the application of proposed methodology
\end{abstract}


relief taxonomy developed by Ross (1992), Florenzano (2008), Technical Manual geomorphology (IBGE, 2009) and image processing routines described in Novo (2008). The geomorphological compartmentation was developed from intermediate cartographic products derived from physiographic analysis (satellite image of Landsat $5 \mathrm{TM}$ and GeoEye) and supported by morphometric of from radar interferometric SRTM (Shuttle Radar Topographic Mission). The mapping geomorphological was characterized by the 5th taxon, where it was possible identify the following units of relief: fluvial plain, hills convex slopes up to $6 \%$, hills convex slope between $6 \%$ and $12 \%$, hills convex slope between $12 \%$ and $20 \%$, small hill top convex and hill top convex. Among the mapped drives predominate dissected relief in convex tops of hills in approximately $90 \%$ of the basin area associated with slopes that do not exceed 20\%, sustained over the Furnas Formation and Aquidauana Formation in essence consists of granulating medium reddish sandstones.

Keywords: Geomorphological Mapping. Taxonomy of Relief. Remote Sensing. GIS. Indaiá Stream.

\section{Introdução}

Durante décadas, os dados remotamente detectados e Sistemas de Informação Geográfica (SIG) têm sido usados com sucesso para o mapeamento e extração de estruturas de superfície e, portanto, representam uma parte integrante da geomorfologia aplicada, conforme descrito em Verstappen (1977), Butler e Walsh (1998), Bocco, Mendoza e Velázquez (2001), Crósta e Souza Filho (2003), Smith, Rose e Booth (2006) e Bubenzer e Bolten (2008).

Geólogos, geógrafos, físicos e outros cientistas rotineiramente utilizam a visão sinóptica proporcionada pelos dados de sensoriamento remoto visando identificar e interpretar feições geomorfológicas na superfície terrestre. De fato, a identificação, o entendimento e a avaliação quanto à natureza das formas de relevo visíveis em imagens de sensores remotos é um dos grandes benefícios da ciência do sensoriamento remoto (Jensen, 2009).

Nesse contexto, o sensoriamento remoto se mostra uma ferramenta muito importante na definição de padrões de relevo, porque possibilita a visualização de grandes áreas, proporciona a noção de profundidade e possibilidade de visão além do visível, otimizando as informações (Novo, 2008). Os dados de sensoriamento remoto implementados em um SIG permitem o estabelecimento de um avanço taxonômico na cartografia do relevo, conferindo desta maneira, bases para o planejamento e ordenamento do território.

Durante mais de 100 anos de mapas geomorfológicos foram utilizados para ilustrar a distribuição espacial das formas de relevo e processos geomorfológicos. As primeiras tentativas apenas representavam recursos ou processos, começando com Gehne (em 1912) e Passarge (em 1914). O mapeamento geomorfológico continuou a se desenvolver e atingiu o seu ápice na década de 1970 (Klimaszewski, 1990). No entanto, antes da introdução dos SIG os procedimentos de cartografia geomorfológica caracterizavam-se como um processo demorado e de difícil integração com outros elementos da paisagem. 
Com o avanço das geotecnologias, a geomorfologia dispõe de uma variedade de dados e técnicas de sensoriamento remoto que fornecem níveis de informação sem precedentes. Os avanços tecnológicos dos novos sensores remotos, que produzem imagens com melhor resolução espacial, espectral, radiométrica e temporal, além do recurso estereoscópico, permitem aos especialistas em geomorfologia mapear, medir e estudar uma variedade de fenômenos geomorfológicos com maior rapidez e precisão (Florenzano, 2008).

A identificação de unidades de relevo (Meijerink, 1988; Giles; Franklin, 1998) vêm sendo desenvolvidas em ambiente computacional, amenizando a demanda de trabalho manual e a subjetividade dessas atividades (Valeriano, 2003). Seguindo essa perspectiva, Trentin, Santos e Robaina (2012), propõe o uso dos SIG nas análises geomorfológicas, uma vez que proporciona uma maior agilidade na realização de levantamento e processamento das informações, facilitando a tarefa de integração, espacialização dos dados e elaboração dos resultados, como o estudo do relevo por meio da compartimentação geomorfológica.

Conforme Penteado-Orelhana (1985), a análise geomorfológica consiste na identificação das formas de relevo, por meio de estudo de sua origem, estrutura, natureza das rochas, clima e dos fatores endógenos e exógenos responsáveis pelo modelado ou pela formação de determinados elementos da superfície terrestre.

Segundo Trentin, Santos e Robaina (2012) os estudos geomorfológicos podem contribuir no planejamento e na conservação dos recursos naturais, estabelecendo formas racionais de uso desses recursos, sem alterar bruscamente o equilibrio do ecossistema. Esses estudos permitiram ainda a análise espaço-temporal dos processos atuantes no modelado do relevo terrestre, possibilitando a identificação ou a prevenção de processos de degradação ambiental que se achem relacionados aos elementos físicos. Desta maneira, a análise geomorfológica insere-se nos estudos ambientais, contribuindo, por seu turno, para orientar a instalação das atividades humanas (Christofoletti, 2001).

Para Tricart (1965), o mapa geomorfológico refere-se à base da pesquisa e não à concretização gráfica da pesquisa realizada, o que demonstra seu significado para melhor compreensão das relações espaciais, sintetizadas através dos compartimentos, permitindo abordagens de interesse geográfico como a vulnerabilidade e a potencialidade dos recursos do relevo. Mapas geomorfológicos são imprescindíveis em estudos e atividades de intervenção no meio físico. Esses mapas fornecem informações relevantes às pesquisas geomorfológicas e são úteis em atividades aplicadas, tais como inventários de recursos naturais, prevenção de desastres e planejamento urbano e rural (Camargo et al., 2012).

Abreu (1982) recorre aos trabalhos soviéticos, desenvolvidos principalmente após a Segunda Guerra Mundial, voltados à análise de grandes e médios espaços, utilizando fundamentalmente o método cartográfico, que tem suas raízes firmemente plantadas na obra de Penck (1924) e teve como pioneiro Gerasimov (1946), que propôs, os conceitos de geotextura, morfoestrutura e morfoescultura" (Gerasimov; Mescherikov, 1968), os quais se equivalem aos conceitos de morfotectura, morfoestrutura e morfoescultura empregados por Mescerjakov (1968).

Seguindo essa linha de pesquisa Russa baseada na concepção de Penck (1953), sobre os processos endógenos e exógenos, nos conceitos de Gerasimov e Mercherikov (1963) e Mercerjakov (1968) sobre morfoestrutura e morfoescultura, e na metodologia desenvolvida pelo 
projeto RadamBrasil, Ross (1992) onde propõe uma classificação em cinco níveis taxonômicos, com base na morfologia e gênese. $\bigcirc$ presente trabalho teve como objetivo a aplicação de SIG e Sensoriamento Remoto no mapeamento geomorfológico da bacia hidrográfica do córrego Indaiá, Aquidauana-MS.

\section{Materiais e métodos}

\section{Caracterização da área de estudo}

A bacia hidrográfica do córrego Indaiá localiza-se no estado de Mato Grosso do Sul, na região sudoeste do município de Aquidauana, entre as latitudes 20009'00" S e 20016'00"

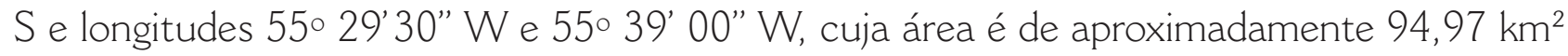
(Figura 1). $\bigcirc$ córrego é afluente do rio Taboco, que por consequência adentra a Planície Pantaneira.

A bacia está inserida no Bioma Cerrado, cuja vegetação primária predominante é a Savana Arbórea Densa (Cerradão) e destaca-se a presença de Agropecuária e Pastagem (Brasil, 1982).

Apresenta precipitação média anual em torno de 1.350 mm (Sant'anna Neto, 1993). Geralmente a média térmica da região é alta, ficando em torno de $25^{\circ} \mathrm{C}$, ao passo que a média mensal do mês mais quente (janeiro) alcança $27,5 \circ \mathrm{C}$ e a dos meses mais frio (junho) chega a 22,5 C. Entretanto, são comuns na região temperaturas superiores a $40 \circ \mathrm{C}$ nos meses de verão e nos meses de inverno, temperaturas mínimas inferiores a 5 ○C (Pinto, 1998).

\section{Figura 1 - Mapa de localização da bacia hidrográfica do córrego Indaiá}

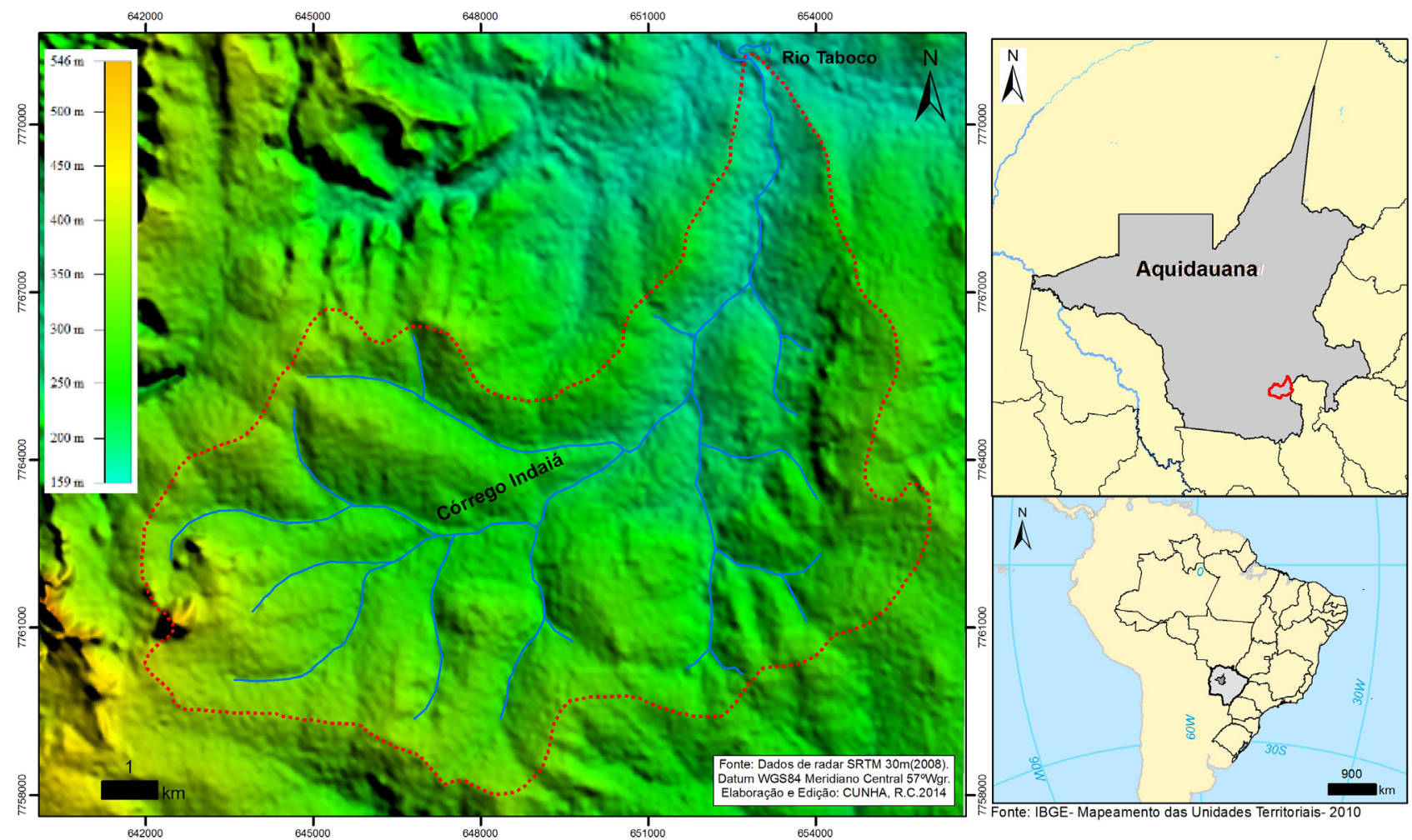


Do ponto de vista geomorfológico a área da bacia está inserida em duas macrounidades morfoestruturais: Bacia Sedimentar do Paraná e Bacia Hidrográfica do Rio Paraguai, subdivididas nas unidades morfoesculturais, Planalto Maracaju- Campo Grande e Depressão do Paraguai (Brasil, 1982).

A geologia é composta por três formações: Formação Furnas (Grupo Paraná) caracterizada pela presença de arenitos quartzoso, grosseiro, tendo intercaladas camadas de arenito extremamente micáceo, apresentando frequentemente estratificação cruzada, Formação Aquidauana predominam siltitos arenosos e arenitos finos a médios e até grosseiros, com predominância dos primeiros, mostrando estratificação nos termos arenosos, cor rosada a vermetho - tijolo é praticamente constante nestes afloramentos. Aluviões Fluviais constituídos por cascalhos grosseiros mal selecionados, com seixos arredondados geralmente em um nível inferior, sobrepostos por bancos essencialmente arenosos de granulação grosseira a fina, contendo níveis siltosos (Brasil, 1982).

Os solos predominantes são: gleissolos de textura arenosa, localizados em toda a planície fluvial; neossolos quartzarênicos de textura arenosa que predominam em mais da metade da área da bacia, encontram-se numa faixa que vai desde algumas de suas nascentes (na margem esquerda) até a proximidade de sua foz com rio Taboco; latossolos vermelhos álicos de textura franco-arenosa desenvolvem ao longo de alguns dos seus tributários (na margem direita) e neossolos litólicos de textura indiscriminada são encontrados nos morro e morrotes, adaptado com base em trabalhos de campo e no Plano de Conservação da Bacia do Alto Paraguai (PCBAP) (Brasil, 1997).

Atualmente, o uso e ocupação do solo no córrego Indaiá, passa por uma expressiva transformação em função da instalação do primeiro complexo de assentamento rural do município de Aquidauana-MS. Em 15 de dezembro de 2009, o Instituto Nacional de Colonização e Reforma Agrária (Incra) realizou o lançamento simultâneo dos quatro primeiros projetos de reforma agrária em Aquidauana-MS. Ao todo, são 252 famílias beneficiadas pelo complexo de 6,4 mil hectares formados pelos assentamentos Indaiá I, II, III e IV (Incra, 2009).

\section{Procedimentos metodológicos}

Os procedimentos técnicos científicos empregados consistiram na aplicação da proposta metodológica da taxonomia do relevo elaborada por Ross (1992), Florenzano (2008), manual técnico de geomorfologia (IBGE, 2009) e rotinas de tratamento de imagem descritas em Novo (2008). A compartimentação geomorfológica foi elaborada a partir de produtos cartográficos intermediários derivados de análises fisiográficas (imagens dos satélites Landsat 5 TM e GeoEye) e morfométricas apoiadas em dados de radar interferométrico SRTM (Shuttle Radar Topographic Mission). Toda elaboração da cartografia digital teve como ambiente de trabalho o software ArcGis 10 (Arcgis/Arcinfo).

Etapas percorridas: análise morfométrica, identificação e caracterização do meio físico (delimitação da bacia hidrográfica do córrego Indaiá, hipsometria, declividade, orientação de vertentes e geomorfologia). 
Delimitação da bacia hidrográfica: o procedimento metodológico para delimitação da bacia hidrográfica do córrego Indaiá consistiu na aplicação metodológica elaborada por Fitz (2008); utilizou-se a carta topográfica Folha Aquidauana (SF 21 - X-A III), na escala de 1:100.000 (DSG-1966), que foi digitalizada em scanner de mesa e dados do radar SRTM 30 m (Valeriano, 2008) quadricula 20_57_ZN (GeoTIFF) extraído do Banco de Dados Geomorfométricos Brasileiro (Topodata), disponível gratuitamente no sítio do Inpe, através do dados de radar SRTM, foram geradas curvas de nível com equidistâncias de 15 m que auxiliaram na delimitação e extração das drenagem.

A modelagem numérica de terreno foi realizada com base em dados de radar SRTM, com resolução original de 90 m, refinados por Krigagem para 30 m por Valeriano (2008). Foi gerado um Modelo de Grade Regular Retangular (MGRR), segundo procedimentos descritos em (Câmara; Monteiro; Medeiros, 2001).

Do modelo se extraiu um Modelo Tridimensional do Relevo, que deu origem aos mapas: hipsométrico, clinográfico e de orientação de vertentes.

Os intervalos adotados para a carta hipsométrica foram: (a) $158 \mathrm{~m}$ a $196 \mathrm{~m}$, (b) $196 \mathrm{~m}$ a 220 m, (c) 220 m a 260 m, (d) 260 m a 300 m, (e) 300 m a 340 m (f) 340 m a 380 m, (g) 380 $\mathrm{m}$ a $420 \mathrm{~m}$, (h) $420 \mathrm{~m}$ a $545 \mathrm{~m}$.

A declividade é o ângulo de inclinação da superfície local em relação ao plano horizontal. A carta clinográfica foi elaborada segundo intervalos estabelecidos por Ross (1994), com a seguinte ordem: (a) 0\% a 6\%, (b) 6\% a 12\%, (c) 12\% a 20\%, (d) 20\% a 30\%, (e) $>30 \%$.

A orientação de vertentes é uma medida de ângulo horizontal da direção esperada de escoamento superficial, expressa em azimute, isto é, em relação ao norte geográfico, onde o valor $0^{\circ}$ (ou 360), crescendo dessa direção, no sentido horário. A carta de orientação de ver-

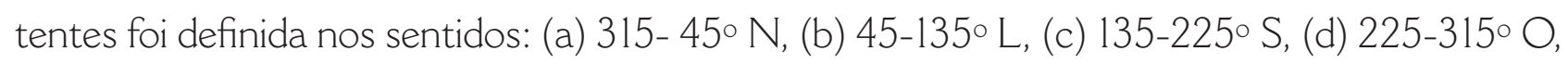
e o padrão de cores adotado foi o proposto por Oliveira (1984).

Ambos os produtos cartográficos a partir do MDT auxiliaram nas etapas seguintes de mapeamento geomorfológico. $\bigcirc$ mapa de unidades do relevo, foi elaborado na escala de 1:35.000 e publicado em 1:100.000, organizado segundo a proposta taxonômica do relevo descrita em Ross (1992). As delimitações das unidades do relevo foram feitas através de interpretação visual de imagens de satélite (Landsat 5 TM e imagens GeoEye extraídas do software Google Earth com a utilização do software Stitch Map) e auxiliada pelos demais produtos derivados do MDT. Nessa perspectiva, o relevo é classificado em seis táxons, sendo o 10 correspondente as morfoestruturas e a partir do 20 até o $6 \circ$ englobam-se as morfoesculturas, padrão de formas, tipos de forma, tipos de vertentes e formas antrópicas.

uso combinado das informações geradas pelas cartas hipsométrica, clinográfica e imagens de satélite permitiu o detalhamento até o 50 táxon, que correspondem aos tipos de vertentes. Como descrito em Ross (1992), nos mapeamentos em escalas médias tipo 
1:50.000, 1:100.000 e 1:250.000, as vertentes não podem ser representadas de modo especializado e, seguindo essa concepção, utilizou-se letras símbolos para indicar os setores de vertentes: vertente convexa $\left(V_{c}\right)$, topo convexo $(T c)$.

\section{Resultados e discussão Hipsometria}

A hipsometria da bacia hidrográfica do córrego Indaiá (Figura 2) apresentou um arranjo de 8 classes altimétricas que variam de $545 \mathrm{~m}$ a $156 \mathrm{~m}$ de altitude, configurando uma amplitude altimétrica de 389 metros. Da foz com o rio Taboco até mais da metade do seu médio curso a amplitude altimétrica é muito baixa (aproximadamente 100 metros). A oeste encontram-se as altitudes mais elevadas com aproximandamente 545 metros associadas a um relevo fortemente ondulado com declividades que ultrapassam $30 \%$. A leste, no sentido à foz com o rio Taboco, ocorrem níveis altimétricos que chegam a aproximadamente 156 metros, onde o relevo oscila entre plano e suave ondulado com declividades que variam de $0 \mathrm{a}$ 20\%. A disposição das cotas altimétricas mais elevadas a oeste e menores a leste evendencia o sentido do escoamento da drenagem $(\mathrm{O}-\mathrm{L})$.

\section{Figura 2 - Mapa hipsométrico da bacia hidrográfica do córrego Indaiá}
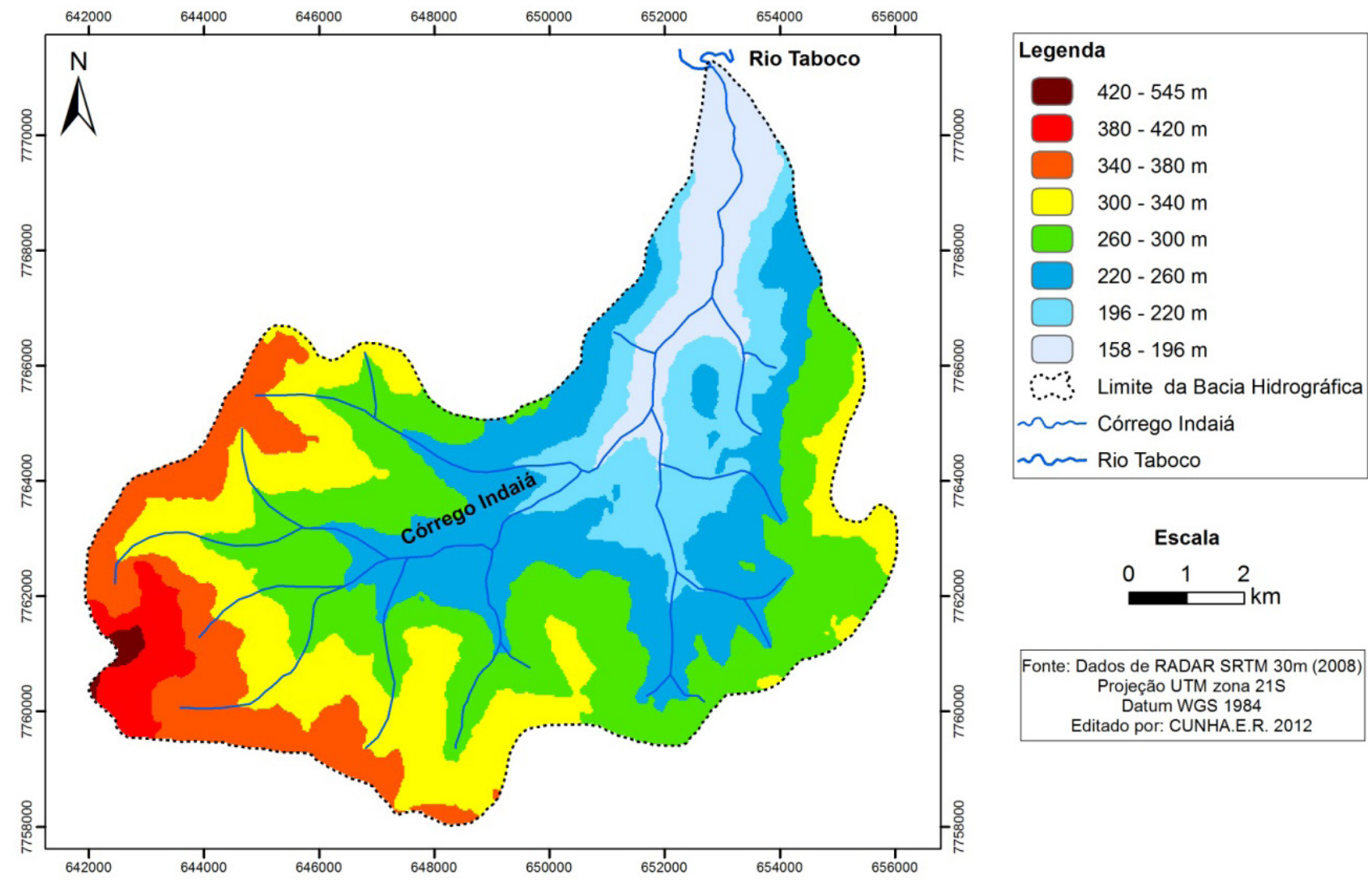
Segundo Mendonça (1999) a identificação e análise da hipsometria da bacia hidrográfica possibilitam a observação da variação altimétrica do relevo da área, fato importante na análise de processos relativos à dinâmica de uso e ocupação e da formação de microambientes da mesma, entre outros.

A Tabela 1 mostra os dados quantificados das 8 classes altimétricas mapeadas da bacia hidrográfica do córrego Indaiá.

Tabela 1 - Quantificação das classes altimétricas

\begin{tabular}{|c|c|c|c|}
\hline classes altimétricas & intervalos altimétricos (metros) & $\mathrm{km}^{2}$ & $\%$ \\
\hline A & $158 \mathrm{~m}$ a $196 \mathrm{~m}$ & 7,4132 & 7,83 \\
\hline B & $196 \mathrm{~m}$ a $220 \mathrm{~m}$ & 11,1438 & 11,77 \\
\hline $\mathrm{C}$ & $220 \mathrm{~m}$ a $260 \mathrm{~m}$ & 19,7483 & 20,86 \\
\hline $\mathrm{D}$ & $260 \mathrm{~m}$ a $300 \mathrm{~m}$ & 24,9950 & 26,40 \\
\hline E & $300 \mathrm{~m}$ a $340 \mathrm{~m}$ & 18,1235 & 19,14 \\
\hline $\mathrm{F}$ & $340 \mathrm{~m}$ a $380 \mathrm{~m}$ & 10,2059 & 10,78 \\
\hline G & $380 \mathrm{~m}$ a $420 \mathrm{~m}$ & 2,6832 & 2,83 \\
\hline \multirow[t]{2}{*}{$\mathrm{H}$} & $420 \mathrm{~m}$ a $545 \mathrm{~m}$ & 0,3365 & 0,39 \\
\hline & total & 94,6494 & 100 \\
\hline
\end{tabular}

\section{Clinografia}

A Tabela 2 apresenta a clinografia da bacia hidrográfica do córrego Indaiá, dividida em cinco classes, segundo graus de fragilidade (Ross, 1994): 0\% a 6\%, 6\% a 12\%, 12\% a 20\%, 20\% a $30 \%$ e acima de $30 \%$.

Tabela 2 - Quantificação das classes de declividade

\begin{tabular}{lrr}
\hline classes de declividades & $\mathrm{km}^{2}$ & $\%$ \\
\hline $0 \%$ a $6 \%$ & 58,5395 & 61 \\
\hline $6 \%$ a $12 \%$ & 33,8190 & 36 \\
\hline $12 \%$ a $20 \%$ & 1,7372 & 2 \\
\hline $20 \%$ a 30\% & 0,2928 & 0,6 \\
\hline acima de 30\% & 0,2442 & 0,4 \\
\hline total & 94,6327 & 100 \\
\hline
\end{tabular}

A partir do mapeamento da clinografia (Figura 3) foi possível identificar o predomínio de inclinações de até 6\% em aproximadamente 61\% da área da bacia hidrográfica, onde encontra-se com formas de relvo praticamente plano e suave ondulado, caracterizado por colinas convexas, localizadas desde as nascentes até a sua foz. 


\section{Figura 3 - Mapa clinográfico da bacia hidrográfica do córrego Indaiá}

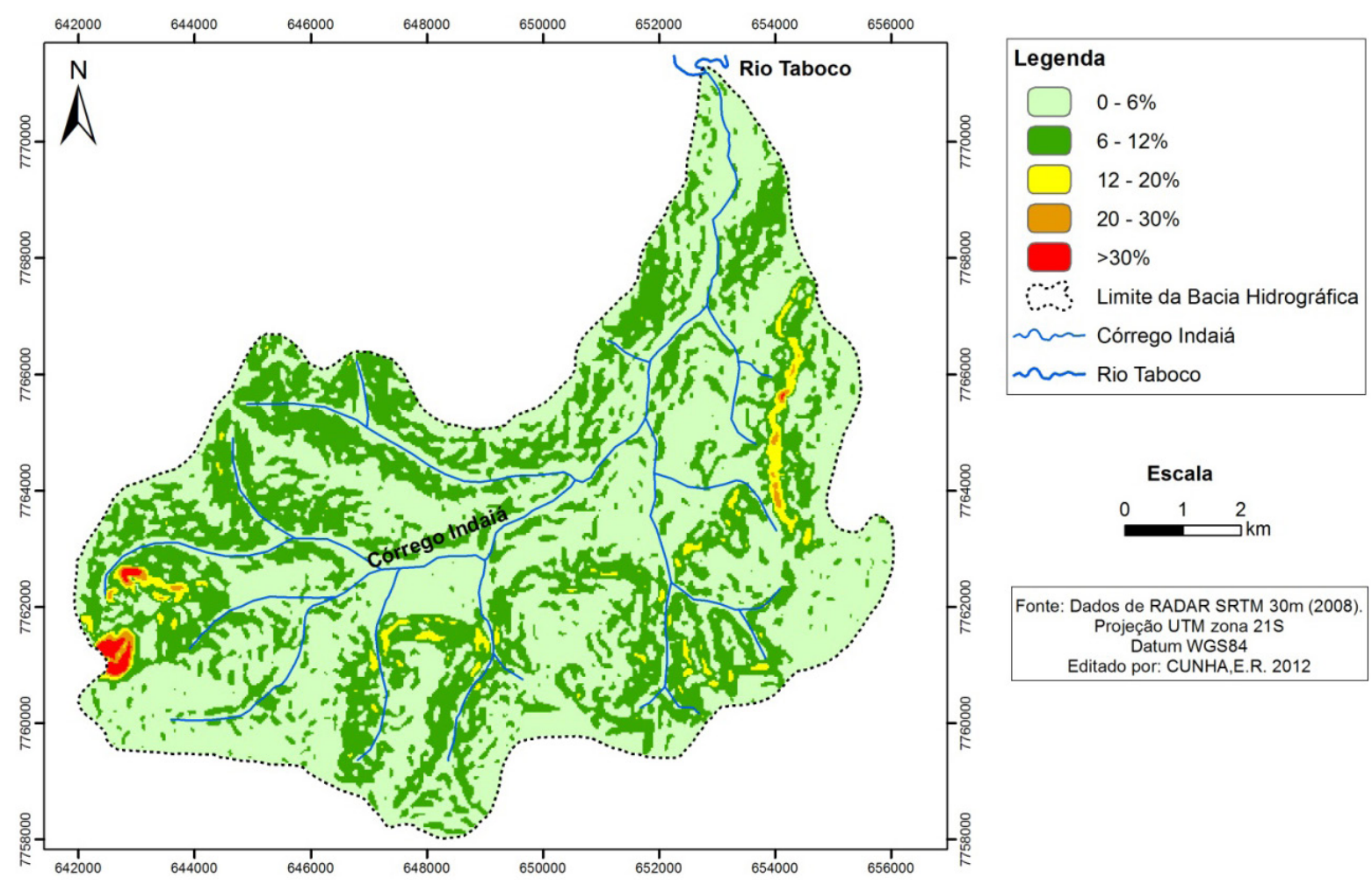

A segunda classe, destaca-se por apresentar as declividades de 6\% a $12 \%$ que abrange aproximandente 36\% de toda bacia. Em seguida, apresenta-se as inclinições de 12\% a 20\% que são encontradas em três áreas: a montante nas proximidades de duas nascentes, ao longo do médio curso na margem direita e a jusante, a margem direita, nas proximidades de três nascentes dos seus tribútarios, correspondendo a aproximadamente $2 \%$ da área total da bacia, caraterizadas pela presença de relevo suave ondulado. As declividades entre $20 \%$ e 30\% correspondem a apenas $0,6 \%$ da área da bacia, localizadas nas sequências das inclinações de $12 \%$ a $20 \%$, e acompanham relevo ondulado. A inclinações maiores que $30 \%$ ocorrem nas áreas onde o relevo apresenta formas fortemente onduladas, caracterizadas pela presença de morrote e morro; compreende uma área de aproximadamente 0,4\% da bacia hidrográfica.

Segundo Villela e Mattos (1975) a declividade relaciona-se com a velocidade em que se dá o escoamento superficial, afetando, portanto, o tempo que leva a água da chuva para concentrar-se nos leitos fluviais que constituem a rede de drenagem das bacias, sendo que os picos de enchente, infiltração e susceptibilidade para erosão dos solos dependem da rapidez com que ocorre o escoamento sobre os terrenos da bacia. Nesse sentido, o predomínio de baixas declividades predominantes na bacia pode se constituir num indicativo de elevada possibilidade de enchentes, sobretudo por se tratar de áreas com inclinações inferiores a $6 \%$ e, em sua grande maioria, conectadas com a rede de drenagem. Essa constatação reforça o pressuposto de Valeriano (2008), ao associar a declividade do terreno como uma variável básica para a segmentação de áreas em praticamente todos os procedimentos de planejamento territorial. 


\section{Orientação de vertentes}

Segundo Tricart (1957), a vertente "constitui o elemento dominante do relevo na maior parte das regiões, apresentando-se, portanto, como forma de relevo mais importante para o homem. Tanto para agricultura, quanto os demais trabalhos de construções".

A orientação de vertentes da bacia hidrográfica do córrego Indaiá (Figura 4) apresenta uma complexidade na disposição das vertentes, fato que justifica os vários sentidos de escoamento de fluxo para a bacia, todavia destacam-se vertentes orientadas para norte $(\mathrm{N})$ e leste (L). Para Lombardo (1996), o fluxo de radiação que chega a uma vertente bastante inclinada e posicionada em direção norte, em área subtropical austral, será mais intenso do que outra, com a mesma inclinação e no mesmo local, posicionada em direção sul.

\section{Figura 4 - Mapa de orientação de vertentes da bacia hidrográfica do cór- rego Indaiá}

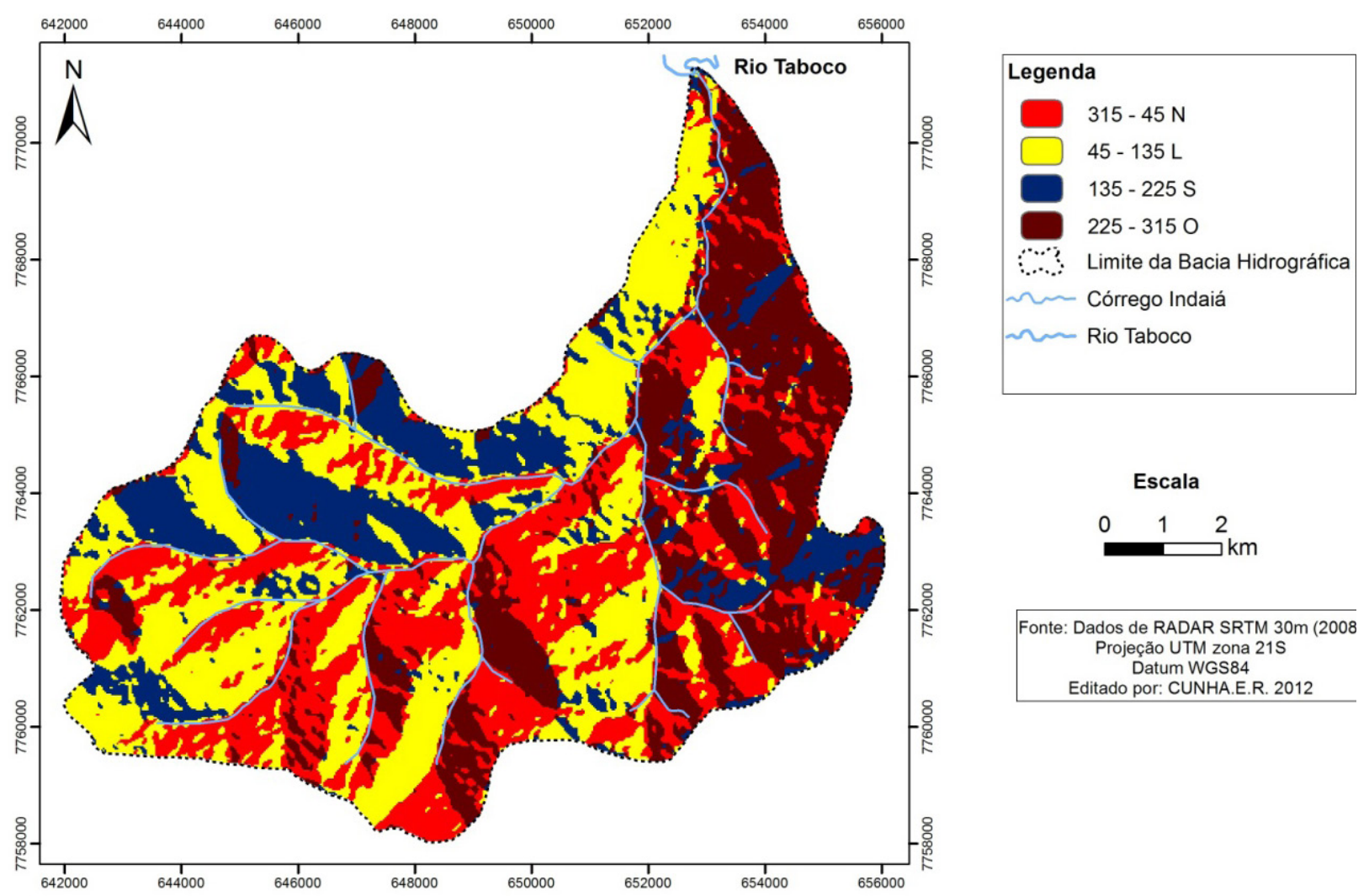

Segundo Lepsch (2002) as superfícies próximas ao trópico de Capricórnio tendem a apresentar vertentes voltadas para o norte mais quentes e secas que as para o sul. É importante salientar que vertentes orientadas para o norte recebem uma quantidade de radiação solar muito superior do que as voltadas para o sul, o que favorece o maior intemperismo dessas vertentes. Tais características estão associadas à presença de solos arenosos combinados com escassos fragmentos de cobertura vegetal decorrente do processo de instalação do complexo de assentamentos Indaiá (I, II, III e IV) que vem juntamente com a atividade da pecuária extensiva sem práticas conservacionistas promovendo a aceleração dos processos erosivos na bacia em questão. 


\section{Geomorfologia}

A Figura 5 apresenta o mapeamento geomorfológico da bacia hidrográfica do córrego Indaiá relacionadas hierarquicamente com as morfoestruturas Bacia Sedimentar do Paraná e morfoescultura do Planalto Maracaju-Campo Grande e suas respectivas unidades geomorfológicas.

\section{Figura 5 - Mapa geomorfológico da bacia hidrográfica do córrego Indaiá}

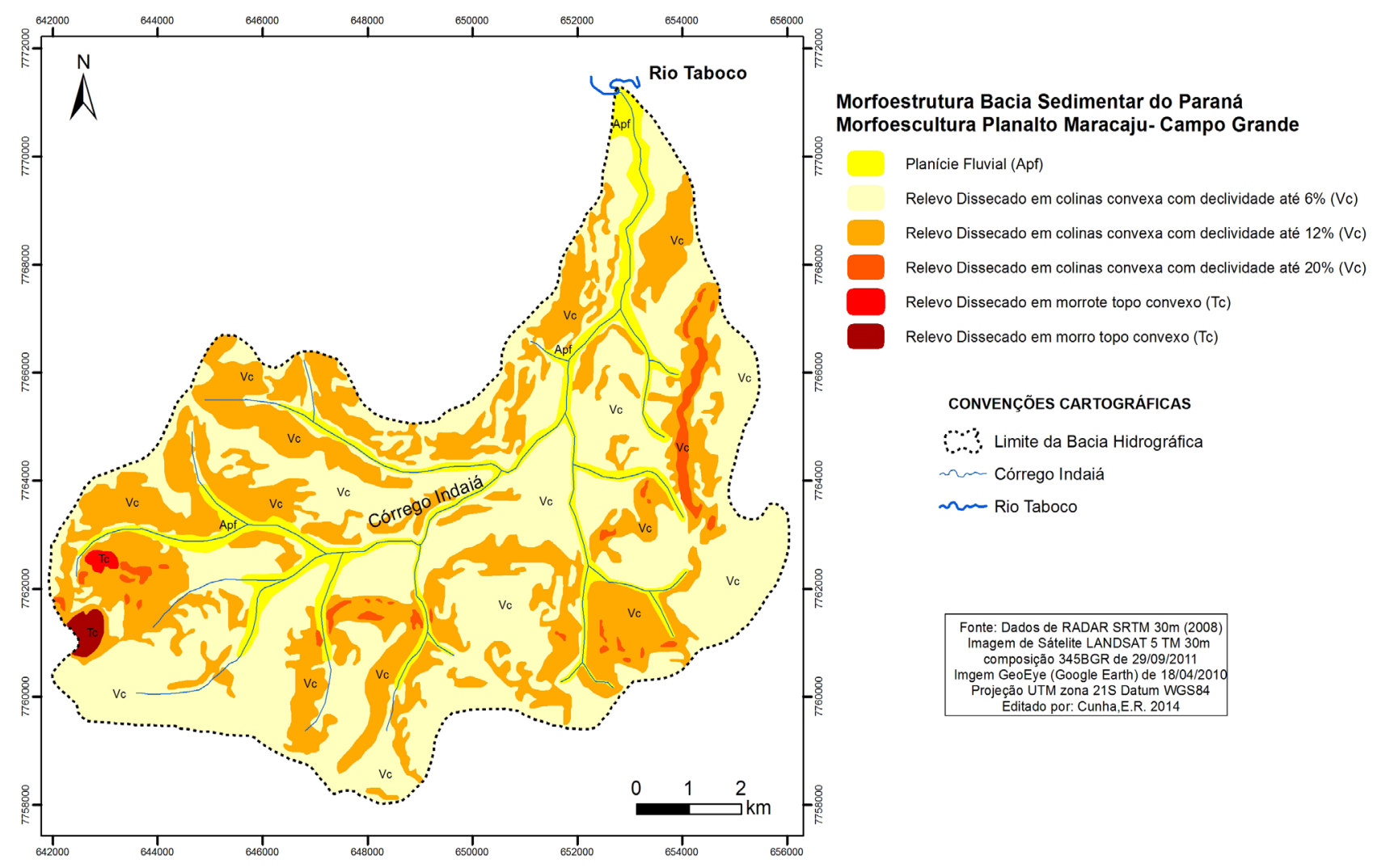

A Geomorfologia foi caracterizada até o 50 táxon onde foram identificadas as seguintes unidades do relevo e suas respectivas formas (vertentes) (Figura 6): (a) planície fluvial (Apf), (b) relevo dissecado em colinas convexas com declividades até 6\% (Vc), (c) relevo dissecado em colinas convexas com declividade entre 6\% a 12\% ( $\mathrm{Vc}$ ), (d) relevo dissecado em colinas convexas com declividade entre 12\% a 20\% (Vc), (e) relevo dissecado em morrote topo convexo (Tc), (f) relevo dissecado em morro topo convexo (Tc).

(a) Planície fluvial (Apf): encontra-se em aproximadamente 8, 95\% da área total da bacia, apresenta cotas altimétricas que variam de 156 m a $340 \mathrm{~m}$ e inclinações que não ultrapassam 6\%, localiza-se ao longo das margens da drenagem desde as proximidades das nascentes até sua foz com rio Taboco. Destaca-se a presença de gleissolos de textura arenosa, caracterizada por um relevo plano associado a uma faixa de mata ciliar, a mesma que nos últimos anos e com mais expressividade em 2011 e 2012 sofreu grande perda de vegetação natural por consequência do desmatamento e queimadas, provavelmente provocadas pelos pequenos proprietários dos lotes do assentamento Indaiá (I, II, III, IV). Essa ação contradiz o Código 
Florestal Brasileiro (Brasil, 2012), que considera essa unidade geomorfológica como área restrita ao uso e ocupação, que se caracteriza como área de preservação permanente (APP) e/ou apresenta elevado risco de inundação.

\section{Figura 6 - Unidades do relevo mapeadas}

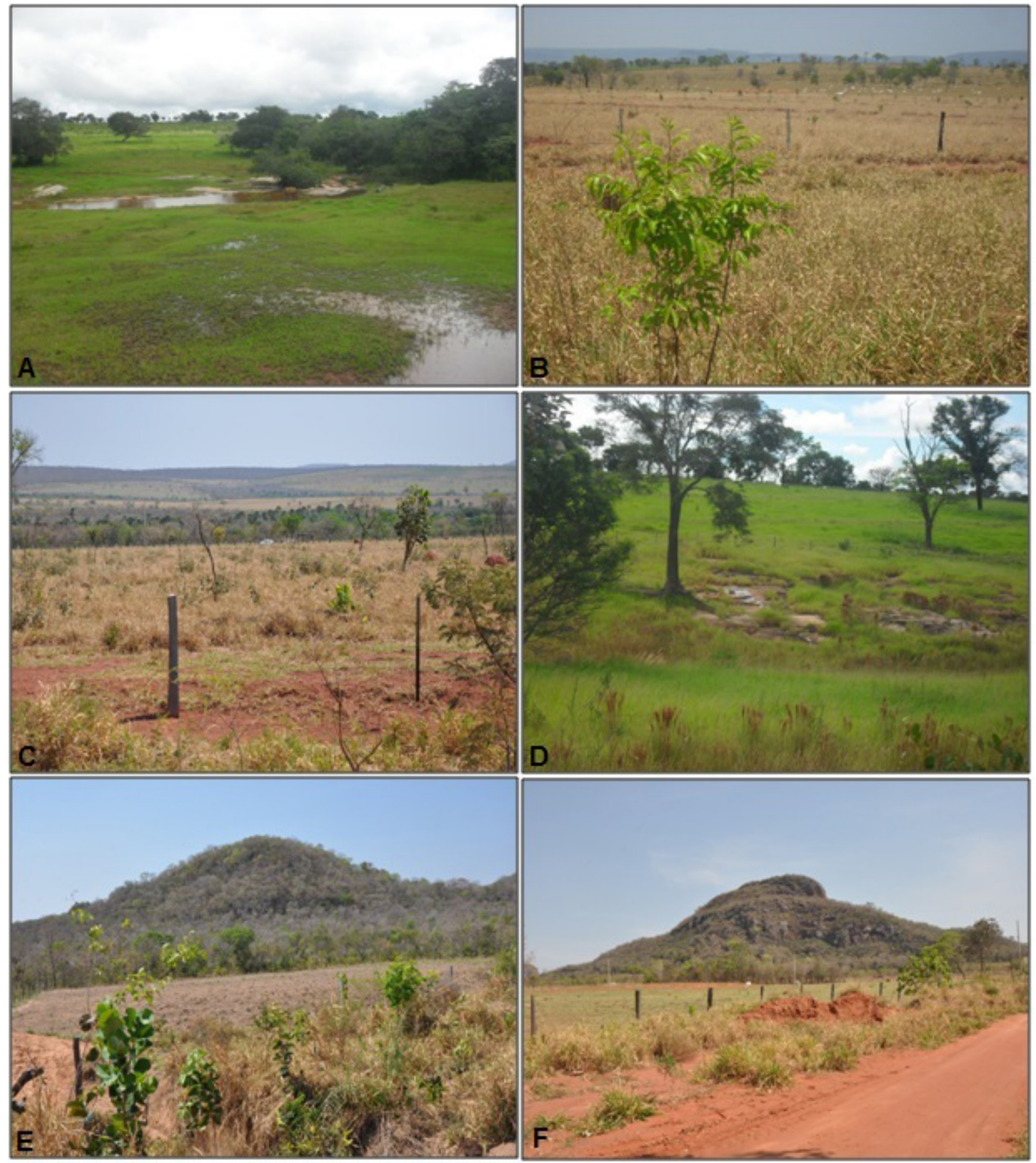

(b) Relevo dissecado em colinas convexas com declividade até $6 \%(\mathrm{Vc})$ : essa unidade apresenta a maior área mapeada da bacia hidrográfica ultrapassando mais de $54 \%$, fazendo limite com a planície fluvial e as colinas convexas com declividade entre 6\% e 
$12 \%$, distribuída por toda a bacia desde as nascentes até sua foz, e apresentam variação altimétrica entre 158 m e 420 m, associado com relevo plano e suave ondulado. Sobre a unidade de relevo os solos que se desenvolvem são: latossolos vermelho álico de textura franco-arenosa e os neossolos quartzarênicos de textura arenosa.

(c) Relevo dissecado em colinas convexas com declividade entre $6 \%$ e 12\% (Vc): compreende a segunda maior área com aproximadamente 34,66\%. Localiza-se ao longo de toda área da bacia, associada às cotas altimétricas que ficam entre $158 \mathrm{~m}$ e $420 \mathrm{~m}$, relevo caracterizado por formas suaves onduladas. Predominam nessa unidade dois tipos de solos de características arenosas: neossolos quartzarênicos e latossolos vermelhos álicos.

(d) Relevo dissecado em colinas convexas com declividade entre $12 \%$ e 20\% (Vc): ocupa aproximadamente 1,54\% da área, limita-se em pequenas porções à margem direita do canal principal, caracterizadas por um relevo de formas onduladas essa unidade está associada ao desenvolvimento de solos arenosos, com predominância de latossolos vermelhos álicos.

(e) Relevo dissecado em morrote topo convexo (Tc): unidade morfológica que corresponde a menor área da bacia com aproximadamente 0,2\%, localiza-se a oeste próximo a principal nascente do córrego Indaiá, com uma variação altimétrica entre 340 m e 420 m, esculturada sobre a Formação Furnas, com predomínio de neossolos litólicos (Brasil, 1982).

(f) Relevo dissecado em morro topo convexo (Tc): encontra-se no extremo oeste da bacia hidrográfica, com variação altimétrica entre 420 m e 545 m, unidade caracterizada por um relevo fortemente ondulado com inclinações acima de 30\% sustentados pela litologia da Formação Furnas caracterizada por arenitos quartzosos, onde se destaca a presença de neossolos litólicos. Por ser uma região de topografia fortemente inclinada, destacam-se encostas sujeitas a deslizamentos.

A Tabela 3 apresenta a quantificação em quilômetros quadrados $\left(\mathrm{km}^{2}\right)$ e porcentagem (\%) das unidades de relevo mapeadas.

Tabela 3 - Quantificação das unidades de relevo mapeadas

\begin{tabular}{lrr}
\hline tipos de unidades de relevo & $\mathrm{km}^{2}$ & $\%$ \\
\hline planície fluvial & 8,4828 & 8,95 \\
\hline relevo dissecado em colinas convexas com declividade $<6 \%$ & 51,3260 & 54,20 \\
\hline relevo dissecado em colinas convexas com declividade de 6\% a 12\% Dc & 32,8405 & 34,66 \\
\hline relevo dissecado em colinas convexas com declividade de 12\% a 20 \%- Dc & 1,4582 & 1,54 \\
\hline morrote de topo convexo & 0,1944 & 0,20 \\
\hline relevo dissecado em morro de topo - Dc & 0,4263 & 0,45 \\
\hline total & 94,7282 & 100 \\
\hline
\end{tabular}




\section{Considerações finais}

Entre as unidades mapeadas, predominam relevos dissecados em colinas de vertentes convexas em aproximadamente $90 \%$ da área da bacia associada a inclinações que não ultrapassam 20\%, sustentada sobre as Formações Furnas e Aquidauana, constituída essencialmente por arenitos de granulação média. Os processos de infiltração são favorecidos pela constituição litológica das unidades que proporcionam uma baixa densidade de drenagem e, consequentemente, o desenvolvimento de colinas média e amplas. Esse domínio morfológico é um dos fatores que influenciou o atual processo de uso e ocupação através da instalação do complexo de assentamentos Indaiá I, II, III e IV. Com a instalação dos assentamentos, acentuou-se a retirada da cobertura vegetal. Essa ação, associada à pecuária sem práticas conservacionistas, vem causando desequilibrios morfológicos (assoreamentos, boçorocas) na bacia.

\section{Referências}

ABREU, A. A. Análise geomorfológica: reflexão e aplicação. Tese (Livre-docência) - Faculdade de Filosofia, Letras e Ciências Humanas, Universidade de São Paulo, São Paulo, 1982.

ARCGIS. ARCINFO. Esri Inc. ArcGis Version 10. Environmental Systems Research Institute Inc. New York, 2012. 1 CD Rom.

BOCCO, G.; MENDOZA, M.; VELÁZQUEZ, A. Remote sensing and GIS-based regional geomorphological mapping: a tool for land use planning in developing countries. Geomorphology, v. 39, n. 3/4, p. 211-219, 2001.

BRASIL. Presidência da República. Casa Civil. Código Florestal Brasileiro. Lei n. 12.651, de 25 de maio de 2012. Diário Oficial da União, Brasília, DF, 2012.

Plano de conservação da bacia do alto Paraguai: análise integrada e prognóstico da Bacia do Alto Paraguai. Brasília: PNMA, 1997.

Ministério das Minas e Energias. Secretaria Geral. Projeto RadamBrasil: Geologia, Geomorfologia, Pedologia, Vegetação e Uso potencial da terra. Rio de Janeiro, 1982.

BUBENZER, O.; BOLTEN, A. The use of new elevation data (SRTM/ASTER) for the detection and morphometric quantification of Pleistocene megadunes (draa) in the eastern Sahara and the southern Namib. Geomorphology, v. 102, n. 2, p. 221-231, 2008.

BUTLER, D.; WALSH, S. The application of remote sensing and geographic information systems in the study of geomorphology: an introduction. Geomorphology, v. 21, n. 3, p. 179-181, 1998.

CÂMARA, G.; MONTEIRO, A. M. V.; MEDEIROS, J. S. Fundamentos epistemológicos da ciência da geoinformação. In: CÂMARA, G.; DAVIS, C.; MONTEIRO, A. M. V. (Org.). Introdução à ciência da geoinformação. São José dos Campos, SP: Inpe, 2001. Disponível em: <http://www.dpi.inpe.br/gilberto/livro/introd/cap5-epistemologia.pdf>. Acesso em: 25 jan. 2015. 
CAMARGO, F. F. et al. Mapeamento geomorfológico com imagens estereoscópicas digitais do sensor Aster/Terra. Geociências, São Paulo, v. 30, n. 1, p. 95-104, 2012.

CASSETI, V. Geomorfologia, 2005. Disponível em: <http://www.funape.org.br/geomorfologia/>. Acesso em: 5 maio 2012.

Ambiente e apropriação do relevo. São Paulo: Contexto, 1991.

CHRISTOFOLETTI, A. Aplicabilidade do conhecimento geomorfológico nos projetos de planejamento. In: GUERRA, A. J. T.; CUNHA, S. B. (Org.). Geomorfologia: uma atualização de bases e conceitos. 4. ed. Rio de Janeiro: Bertrand Brasil, 2001. p. 415-440.

CRÓSTA, A. P.; SOUZA FILHO, C. Targeting key alteration minerals in epithermal deposits in Patagonia, Argentina, using ASTER imagery and principal component analysis. International Journal of Remote Sensing, v. 24, n. 21, p. 4233-4240, 2003.

FITZ, P. R. Cartografia Básica. São Paulo: Oficina de Textos, 2008.

FLORENZANO, T. G. Geomorfologia: conceitos e tecnologias atuais. São Paulo: Oficina de Textos, 2008.

GEHNE, H. Geomorphologische Karte der Umgebung von Thale nach eine neue Methode auf Grund eigener Beobachtungen dargestellt, Mitteilungen des Sächsisch-thüringischen Vereins für Erdkunde zu Halle a. S. Erdkunde, v. 36, p. 1-8, 1912.

GERASIMOV, I. P. Essai d' interprétation géomorphologique du schéma general de la structure géologique de l'URSS. Problèmes de Géographie Physique, Moscou, v. 12, 1946. ; MESCHERIKOV, J. A. Morphostructure. In: FIRBRIDGE, R. W. (Ed.). The Encyclopedia of Geomorphology. New York: Reinhold, 1968. p. 731-732.

GILES, P.T.; FRANKLIN, S. E. An automated approach to the classification of the slope units using digital data. Geomorphology, v. 21, n. 3/4, p. 251-264, 1998.

IBGE. Instituto Brasileiro de Geografia e Estatística. Coordenação de Recursos Naturais e Estudos Ambientais. Manual técnico de geomorfologia. 2. ed. Rio de Janeiro: IBGE, 2009. (Manuais Técnicos em Geociências, n. 5.)

INCRA. Instituto Nacional de Colonização e Reforma Agrária, 2009. Disponível em: <http:// www.incra.gov.br/incra-lanca-complexo-de-assentamentos-em-aquidauana>. Acesso em: 21 maio 2012.

JENSEN, J. R. Sensoriamento remoto do ambiente: uma perspectiva em recursos terrestres. 2. ed. Tradução por pesquisadores do INPE: J. C. N. Epiphanio (Coord.), A. R. Formaggio, A. R. Santos, B. F. T. Rudorff, C. M. Almeida, L. S. Galvão. São José dos Campos: Parêntese, 2009.

KLIMASZEWSKI. Thirty years of gemorphological mapping. Geographia Polonica, v. 58, p. 11-19, 1990.

LEPSCH, I. F. Formação e conservação dos solos. São Paulo: Oficina de Textos, 2002. 
LOMBARDO, M. A. O clima e a cidade. Boletim Climatológico, Presidente Prudente: Editora da UNESP, ano 1, n. 2, 1996.

MEIJERINK, A. M. J. Data acquisition and data capture through terrain mapping units. ITC Journal, v. 1988, n. 1, p. 23-44, 1988.

MENDONÇA, F. Diagnóstico e análise ambiental de microbacia hidrográfica: proposição metodológica na perspectiva do zoneamento, planejamento e gestão ambiental. RA'EGA - O espaço geográfico em análise, Curitiba, v. 3, p. 2177-2738, 1999.

MESCERJAKOV, J. P. Les concepts de morphostructure et de morphosculture: um nouvel instrument de l'analyse geomorphologique. Annales de Geographie, Paris, v. 77, n. 423, p. 538-552, 1968.

MONTEIRO, A. M. V.; PAIVA, J. A.; D'ALGE, J. C. L. (Org.). Geoprocessamento teria e aplicação, 2000. Disponível em: <http://www.dpi.inpe.br/ gilberto/livro/>. Acesso em: 7 maio 2012.

NOVO, E. M. L. M. Sensoriamento remoto: princípios e aplicações. São Paulo: Edgard Blucher, 2008.

OLIVEIRA, M. C. Construção de uma carta para determinação de orientação de vertentes. Revista do Instituto Geológico, São Paulo, v. 5, n. 1/2, p. 47-50, jan./dez. 1984.

PASSARGE, S. Morphologischer Atlas. Lieferung I: Morphologie des Messtischblattes Stadtremda, Mitteilungen der Geographischen Gesellschaft in Hamburg, v. 28, 1914.

PENCK, W. Morphological Analysis of Landforms. Londres: McMillan, 1953.

Die morphologische analyse: ein kapitel der physikalis chen geologie. Stuttgart: J. Engelhorn's Nachf, 1924.

PENTEADO-ORELHANA, M. M. Metodologia integrada no estudo do meio ambiente. Geografia, Rio Claro, v. 10, n. 20, p. 125-148, out. 1985.

PINTO, A. L. Saneamento básico e suas implicações na qualidade das águas subterrâneas da cidade de Anastácio (MS). Tese (Doutorado em Geociências) - Instituto de Geociências e Ciências Exatas, Universidade Estadual Paulista, Rio Claro, 1998.

ROSS, J. L. S. Análise empírica da fragilidade dos ambientes naturais e antropizados. Revista do Departamento de Geografia, São Paulo: FFLCH-USP, v. 8, p. 17-29, 1994.

O registro cartográfico dos fatos xenomórficos e a questão da taxonomia do relevo. Revista do Departamento de Geografia, São Paulo: FFLCH-USP, v. 6, p. 17-29, 1992.

SANT'ANNA NETO, J. L. O caráter transicional do clima e a diversidade da paisagem natural na região de Aquidauana. In: II SEMANA DE ESTUDOS GEOGRÁFICOS: DESENVOLVIMENTOS E GEOGRAFIA, 2., 1993, Aquidauana. Anais... Aquidauana: UFMS/CEUA, 1993. v. 1. p. 4188-128. 
SMITH, M.; ROSE, J.; BOOTH, S. Geomorphological mapping of glacial landforms from remotely sensed data: an evaluation of the principal data sources and an assessment of their quality. Geomorphology, v. 76, n. 1/2, p. 148-165, 2006.

TRENTIN, R.; SANTOS, L. C. S; ROBAINA, L. R. S. Compartimentação geomorfológica da bacia hidrográfica do rio Itu, no oeste do Rio Grande do Sul - Brasil. Sociedade $\boldsymbol{E}$ Natureza, Uberlândia, v. 24, n. 1, 127-142, jan./abr. 2012.

TRICART, J. Principes et méthodes de 1 geomorphologie. Paris: Masson, 1965. . Mise em point: l'évolution des versants. L'Information Geographique, n. 21, p. 108-115, 1957.

VALERIANO, M. M. Topodata: guia de utilização de dados geomorfométricos locais. São José dos Campos: Inpe, 2008.

; CARVALHO JÚNIOR, O. A. Geoprocessamento de modelos digitais de elevação para mapeamento da curvatura horizontal em microbacias. Revista Brasileira de Geomorfologia, v. 4, n. 1, p. 17-29, 2003.

VERSTAPPEN, H. Remote Sensing in Geomorphology. Amsterdan: Elsevier, 1977.

VILLELA, S. M.; MATTOS, A. Hidrologia aplicada. São Paulo: McGraw Hill, 1975. 